\title{
HUBUNGAN PENDIDIKAN KESEHATAN TENTANG FAKTOR PENYEBAB ASMA DENGAN KEKAMBUHAN ASMA DI RS PKU MUHAMMADIYAH DELANGGU
}

\author{
Tri Yuniarti, Rejo \\ Prodi DIII Perawat STIKES Mambaul Ulum Surakarta, Jawa Tengah, Indonesia
}

\begin{abstract}
Abstrak
Latar Belakang. Asma adalah penyakit peradangan saluran pernafasan. Kekambuhan asma dapat dipicu oleh beberapa faktor seperti lingkungan, makanan, udara dingin dan emosi. Pendidikan kesehatan merupakan aplikasi atau penerapan di bidang kesehatan dalam kehidupan sehari-hari. Peningkatan pendidikan kesehatan tentang kekambuhan asma dapat dilakukan dengan penyuluhan kesehatan.

Tujuan Penelitian. Untuk mengetahui hubungan pendidikan kesehatan tentang faktor penyebab asma dengan kekambuhan asma di RS PKU Muhammadiyah Delanggu.

Subjek dan Metode. Subjek penelitian sebanyak 25 responden dan data dianalisis menggunakan Chi Square.

Hasil Penelitian. Hasil analisis uji Chi Square dengan menggunakan alternative linear by linear dengan hasil $x^{2}=5,538$ dan $p$-value $=0,019$ sehingga ada hubungan yang signifikan antara pendidikan kesehatan tentang faktor pernyebab asma terhadap kekambuhan asma di RS PKU Muhammadiyah Delanggu.

Kesimpulan. Terdapat hubungan pendidikan kesehatan tentang faktor penyebab asma dengan kekambuhan asma di RS PKU Muhammadiyah Delanggu.

Kata kunci: asma, kekambuhan asma, pendidikan kesehatan

\section{THE RELATIONSHIP OF HEALTH EDUCATION ABOUT THE FACTORS THAT CAUSE ASTHMA WITH RELAPSE ASTHMA IN PKU MUHAMMADIYAH DELANGGU GENERAL HOSPITAL}

\begin{abstract}
Background. Asthma is a respiratory disease of the respiratory tract. Recurrence of asthma can be triggered by several factors such as environment, food, cold air, and emotion. Health education is an application or application in the field of health in everyday life. Increased health education on the relapse of asthma can be done with health counseling.

The Aim of the Study. To determine the relationship of health education about the factors that cause asthma relapse asthma in PKU Muhammadiyah Delanggu General Hospital.

Subject and Method. Research subjects were 25 respondents and data were analyzed using Chi Square.

Result. Based on analysis test by using chi square analysis with linear alternatives by linear $x^{2}=5.538$ and $p$-value $=0.019$ so that there was of significant relation between health education about factor of asthma cause to asthma relapse at PKU Muhammadiyah Delanggu General Hospital $(p=0.019)$.

Conclusion: There is a relationship of health education about factors causing asthma to asthma relapse at PKU Muhammadiyah Delanggu General Hospital.
\end{abstract}

Keywords: Asthma, Asthma Relapse, Health Education

Korespondensi: Tri Yuniarti. STIKES Mambaul Ulum Surakarta, JI.Ring Road Utara KM. 03 Tawangsari, Mojosongo, Jebres Surakarta. Email: yuniartitri3006@gmail.com. 
LATAR BELAKANG

Asma adalah penyakit paru kronik yang sering terjadi di dunia. Data mengenai kematian akibat asma mengalami peningkatan dalam beberapa dekade terakhir (McPhee dan Ganong, 2010). Kekambuhan asma dapat dipicu oleh beberapa faktor seperti lingkungan, makanan, udara dingin dan emosi. Lingkungan yang dipenuhi asap rokok, asap kendaraan dan debu merupakan awal timbulnya penyakit asma. Beberapa makanan seperti junk food yang tinggi kadar MSG dan pengawetnya, minuman dingin atau es, coklat dan kacang dapat menjadi penyebab kekambuhan asma.

Gangguan emosi dapat menjadi pencetus terjadinya serangan asma, selain itu juga bisa memperberat serangan asma yang sudah ada. Disamping gejala asma harus segera diobati penderita asma yang mengalami stres harus diberi nasehat untuk menyelesaikan masalahnya. Asma akan mudah kambuh pada cuaca lembab dan hawa yang dingin sering mempengaruhi asma, perubahan cuaca menjadi pemicu serangan asma. Kadang serangan berhubungan asma seperti: musim hujan, musim bunga, musim kemarau. Hal ini berhubungan dengan angin, serbuk bunga dan debu (Wahid dan Suprapto, 2013).

Angka kejadian penyakit asma tahun 2011 mengalami peningkatan dan relatif sangat tinggi dengan banyaknya morbiditas dan mortalitas. Berdasarkan data WHO Non Communicable Disease di Asia Tenggara diperkirakan bahwa 1,4 juta orang meninggal dunia karena penyakit paru kronik dimana $86 \%$ disebabkan karena penyakit paru obstruktif kronik, dan $7,8 \%$ disebabkan karena asma. WHO fact sheet 2011, menyebutkan bahwa terdapat 235 juta orang menderita asma di dunia, $80 \%$ berada di negara dengan pendapatan rendah dan menengah, termasuk Indonesia. Penyakit saluran pernapasan yang menyebabkan kematian terbesar adalah Tuberculosis $(7,5 \%)$ dan Lower Tract Respiratory Disease $(5,1 \%)$. Berdasarkan data Sistem Informasi Rumah Sakit (SIRS) di Indonesia didapatkan bahwa angka kematian akibat penyakit asma adalah sebanyak 63.584 orang. Dari data Riskesdas 2013, pasien asma di Indonesia paling banyak dialami oleh golongan menengah ke bawah dan terbawah (tidak mampu), persentase untuk menengah ke bawah sebanyak $4,7 \%$ dan terbawah 5,8\% (Depkes, 2014).

Prevalensi kasus asma di Jawa Tengah dari tahun ke tahun mengalami penurunan. Kasus asma pada tahun 2010 sebesar 1,09\%, tahun 2011 sebesar $0,69 \%$, tahun 2012 sebesar $0,68 \%$ dan tahun 2013 sebesar 0,58\%. Kasus penyakit asma terbesar di Jawa Tengah yaitu di Kota Semarang. Jumlah penderita Asma tahun 2011 di Semarang sebanyak 17.670 kasus, Kabupaten Brebes sebesar 15.317 kasus, Kabupaten Klaten sebesar 14.718 kasus. Terendah di Kabupaten Batang sebesar 1.378 kasus. Tahun 2012 di wilayah Jawa Tengah sebesar 17.814 kasus dan 2013 sebesar 17.875 kasus.

Kejadian asma menurut jenis kelamin tahun 2011 laki-laki ada 8.285 penderita asma, perempuan ada 9.385 penderita asma (Depkes $\mathrm{RI}, 2014)$. Menurut kelompok umur 15-44 tahun ada 5.470 penderita asma, umur 45-64 tahun ada 7.432 penderita asma, dan 65 tahun ada 2.328 penderita asma (Depkes RI, 2014). Dari data tersebut di Kota Semarang menjadi kota terbesar kasus penyakit tidak menular yaitu penyakit asma. Berdasarkan data dari rekam medis RS PKU Muhammadiyah Delanggu, penderita asma pada tahun 2016 adalah 129 penderita. 
Frekuensi kekambuhan asma tergantung pada sejauh mana pasien mengetahui dan menghindari alergen atau faktor pemicu penyebab kekambuhan asma tersebut. Kurangnya pengetahuan dan pendidikan keluarga terhadap kekambuhan asma menyebabkan tingginya resiko yang terjadi. Oleh karena itu, peneliti tertarik untuk meneliti tentang efektivitas pendidikan kesehatan tentang faktor penyebab asma terhadap kekambuhan asma di RS PKU Muhammadiyah Delanggu.

\section{TUJUAN PENELITIAN}

Untuk mengetahui hubungan pendidikan kesehatan tentang faktor penyebab asma dengan kekambuhan asma di RS PKU Muhammadiyah Delanggu.

\section{METODE}

Penelitian ini merupakan penelitian analitik observasional dengan desain korelasi dan rancangan yang digunakan adalah cross sectional. Teknik pengambilan data dengan sampling non probability dengan metode purposive sampling. Data dianalisis menggunakan uji Chi Square.

\section{SUBJEK}

Populasi dalam penelitian ini adalah 129 orang dengan kriteria pasien penderita asma di RS PKU Muhammadiyah Delanggu yang positif menderita asma dan pasien yang ada di poli paru RS PKU Muhammadiyah Delanggu. Kriteria eksklusi pasien penderita asma yang tidak mau menjadi responden dan penderita asma yang tidak diperbolehkan keluarganya menjadi reponden. Sampel diambil $20-25 \%$ dari populasi sehingga jumlah sampel 25 orang. Pengujian data dilakukan dengan Chi-Square untuk menguji hubungan pendidikan kesehatan tentang faktor penyebab asma terhadap kekambuhan.
HASIL PENELITIAN

Dalam penelitian ini didapatkan hasil sebagai berikut:

Tabel 1.

Karakteristik Responden

\begin{tabular}{lcc}
\hline Karakteristik & $\mathrm{f}$ & $\%$ \\
\hline Jenis kelamin & & \\
Laki-laki & 12 & 48 \\
Perempuan & 13 & 52 \\
Usia & & \\
25 s/d 34 th & 6 & 24 \\
38 s/d 68 th & 19 & 76 \\
Tingkat Pendidikan & & \\
SMA dan Perguruan Tinggi & 7 & 28 \\
SMP, SD dan Tidak & 18 & 72 \\
Sekolah & & \\
\hline
\end{tabular}

Tabel 1 menunjukkan responden berdasarkan jenis kelamin diketahui bahwa jenis kelamin responden paling banyak adalah perempuan yaitu 13 reponden (52\%), berdasarkan usia menunjukkan bahwa usia responden paling banyak dengan rentang usia $35 \mathrm{~s} / \mathrm{d}$ 68 tahun yaitu 19 responden $(76 \%)$, dan berdasarkan tingkat pendidikan menunjukkan bahwa tingkat pendidikan responden mayoritas adalah tamat SMP, SD dan Tidak Sekolah yaitu 18 responden (72\%).

Tabel 2.

Distribusi Frekuensi Responden Berdasarkan Pendidikan Kesehatan di RS PKU Muhammadiyah Delanggu tahun 2017

\begin{tabular}{lcc}
\hline Karakteristik & $\mathrm{f}$ & $\%$ \\
\hline Mendapatkan penkes & 12 & 48 \\
Tidak mendapatkan penkes & 13 & 52 \\
\hline \multicolumn{1}{c}{ Total } & 12 & 48 \\
\hline
\end{tabular}

Hasil distribusi frekuensi responden berdasarkan Tabel 2 menunjukkan bahwa mayoritas responden tidak mendapat pendidikan kesehatan tentang faktor penyebab asma yaitu 13 responden (52\%). 
Tabel 3.

Distribusi Frekuensi Responden

Berdasarkan Kekambuhan Asma di RS PKU Muhammadiyah Delanggu tahun 2017

\begin{tabular}{lcc}
\hline Kekambuhan Asma & $f$ & $\%$ \\
\hline Kambuh $>2 \mathrm{x}$ & 15 & 60 \\
Kambuh 2x & 5 & 20 \\
Baru sekali & 5 & 20 \\
\hline \multicolumn{1}{c}{ Total } & 25 & 100 \\
\hline
\end{tabular}

Hasil distribusi frekuensi responden berdasarkan Tabel 3 menunjukkan bahwa kekambuhan asma mayoritas responden sudah pernah menderita asma dan mengalami kekambuhan lebih dari 2 kali yaitu 15 responden $(60 \%)$.

Tabel 4.

Hubungan Pendidikan Kesehatan tentang Faktor Penyebab Asma dengan Kekambuhan Asma

di RS PKU Muhammadiyah Delanggu tahun 2017

\begin{tabular}{|c|c|c|c|c|c|}
\hline \multirow[b]{2}{*}{ Penkes } & \multicolumn{3}{|c|}{ Kekambuhan Asma } & \multirow[b]{2}{*}{$x^{2}$} & \multirow[b]{2}{*}{$p$} \\
\hline & $\begin{array}{c}\text { Kambuh } \\
>2 x\end{array}$ & $\begin{array}{c}\text { Kambuh } \\
2 x\end{array}$ & $\begin{array}{l}\text { Baru } \\
1 \mathrm{x}\end{array}$ & & \\
\hline Pernah & 2 & 3 & 7 & 5,538 & 0,019 \\
\hline Tidak & 3 & 2 & 8 & & \\
\hline Total & 5 & 5 & 15 & & \\
\hline
\end{tabular}

Dari Tabel 4 di atas menunjukkan bahwa hasil analisis menggunakan uji Chi Square tidak memenuhi syarat dan ketentuan Chi-Square ditunjukkan dengan adanya 4 sel $(6,7 \%)$ mempunyai expected $<5$ maka peneliti menggunakan alternatif linear by linear dengan hasil $X^{2}=5,538$ dan $p$-value $=0,019$ adalah signifikan karena $p<0,05$. Dengan demikian dapat dinyatakan bahwa ada hubungan yang signifikan antara pendidikan kesehatan dengan kekambuhan asma.

\section{PEMBAHASAN}

Tingginya prevalensi kekambuhan asma pada perempuan berhubungan dengan cara perempuan dalam melaporkan gejalanya, bahwa perempuan lebih sering berobat ke rumah sakit, sehingga menyebabkan banyaknya data berjenis kelamin perempuan yang didapatkan. Selain itu juga dapat dihubungkan berdasarkan teori bahwa laki-laki saat dilahirkan memang mempunyai ukuran paru lebih kecil dibandingkan dengan perempuan, tetapi saat remaja dan dewasa ukuran paru-paru pada lakilaki akan lebih besar dibandingkan perempuan (Astma, 2012).

Pengetahuan dapat dipengaruhi oleh beberapa faktor, salah satunya yaitu usia. Usia dapat mempengaruhi pengetahuan seseorang, karena semakin bertambahnya usia maka semakin berkembang pula daya tangkap dan pola pikir seseorang sehingga pengetahuan yang diperoleh pun semakin baik. Namun terjadi penurunan daya tangkap pada usia lanjut yang dipengaruhi oleh faktor fisiologis sehingga tingkat pengetahuan yang dimilikipun juga mengalami penurunan. Dalam penelitian ini usia yang paling banyak adalah pada kelompok usia 38-68 tahun, merupakan usia matang, dimana seseorang pada umur tersebut akan memiliki pola tangkap dan daya pikir yang baik sehingga pengetahuan yang dimilikinya juga akan semakin membaik (Simamora, 2019).

Seiring bertambahnya usia seseorang maka bertambah pula pengalaman seseorang yang melibatkan panca indra yang dapat mempengaruhi pengetahuan (Simamora, 2017). Hal ini sesuai dengan teori yang mengatakan semakin cukup usia seseorang maka tingkat kematangan dan kekuatan seseorang akan lebih matang dalam berfikir. Bertambahnya usia seseorang dapat berpengaruh pada bertambahnya pengetahuan yang diperoleh, tetapi pada usia-usia tertentu atau menjelang usia lanjut kemampuan penerimaan atau 
pengingatan suatu pengetahuan akan berkurang (Hendro, 2012). Usia akan memberikan gambaran pengalaman yang telah dilaluinya. Pengalaman merupakan guru yang terbaik (experience is the best teacher), pepatah tersebut bisa diartikan bahwa pengalaman merupakan sumber pengetahuan, atau pengalaman itu merupakan cara untuk memperoleh suatu kebenaran pengetahuan. Oleh sebab itu pengalaman pribadi pun dapat dijadikan sebagai upaya untuk memperoleh

(Simamora, 2019).

Tingkat pendidikan merupakan indikator bahwa seseorang telah menempuh jenjang pendidikan formal, namun bukan berarti seseorang telah menguasai beberapa bidang ilmu termasuk dalam faktor penyebab kekambuhan asma. Seseorang dengan pendidikan yang baik lebih matang terhadap proses perubahan dirinya, sehingga lebih mudah memperoleh pengaruh luar yang positif, obyektif dan terbuka terhadap berbagai informasi termasuk informasi tentang kesehatan (Notoatmojo, 2012). Pengetahuan atau kognitif merupakan domain yang sangat penting dalam membentuk tindakan seseorang (overt behaviour) saat dilakukan penyuluhan, kondisi akan mempengaruhi minat pasien dalam menyimak penyuluhan yang diberikan. Semakin tinggi minat seseorang terhadap suatu hal, maka akan semakin tinggi tingkat pengetahuannya. Menurut Slameto (2010) minat adalah suatu rasa lebih suka dan rasa ketertarikan pada suatu hal atau aktivitas, tanpa ada yang menyuruh. Minat pasien harus ditumbuhkan agar pasien dapat bekerja sama selama menjalani perawatan di rumah sakit, untuk itu, perlu memberikan motivasi dalam bentuk beragam agar tercipta suasana dan kondisi yang samasama menguntungkan, baik untuk pasien maupun buat petugas kesehatan yang memberikan layanan asuhan.

Putra (2014), menyatakan bahwa pendidikan kesehatan dapat mempengaruhi seseorang dengan cara memberikan informasi secara langsung mengenai hal-hal yang masih belum dimengerti.

Berdasarkan hasil penelitian kekambuhan sering disebabkan oleh faktor pengetahuan dan pendidikan kesehatan dan tidak ada kemauan untuk segera mencegah kekambuhan asma, seringnya terpapar oleh faktor pencetus serta kurangnya dukungan dari keluarga dalam mencegah kekabuhan asma (Wolagole, 2012).

Hasil penelitian ini didukung dari Munawaroh (2014), menyatakan pendidikan kesehatan melalui metode ceramah terbukti lebih efektif dalam upaya mencegah kekambuhan asma. Hasil yang sama pada penelitian Setiyarini (2016), metode pendidikan individual lebih efektif dibandingkan dengan pemberian media leaflet dalam pencegahan penyakit asma.

\section{KESIMPULAN}

Ada hubungan yang signifikan antara pendidikan kesehatan dengan kekambuhan asma. Dengan tingkat pengetahuan yang baik maka mempunyai kecenderungan untuk dapat mencegah kekambuhan asma lebih baik.

\section{SARAN}

Perlunya pemberian informasi melalui brosur, majalah, selebaran tentang edukasi mengenai asma, bagaimana cara mencegah kekambuhan asma yang baik, kegiatan fisik apa yang baik untuk asma, serta hal-hal apa yang harus dihindari bagi seseorang yang memiliki riwayat asma. 
DAFTAR PUSTAKA

Astma. 2012. (GINA) Global Initiative For Astma.

http://www.gina.astma.org.

Diakses pada tanggal 3 Januari 2017.

Depkes RI. 2014. Buku Pedoman Asma. Jakarta.

Hendro. 2012. Hubungan

Pengetahuan Perawat dengan Penerapan Identify Patient Correctly di RSUP Ratatotok Buyat Kabupaten Minahasa Tenggara.

http://media.neliti.com/media/pib lications/105324-ID-hubungan-

perawat-dengan-pene.pdf.

Diakses pada tanggal 20 Juni 2019.

McPhee, S. J. dan Ganong, Wiliam F. 2010. Patofisiologi Penyakit. EGC, Jakarta.

Munawaroh, Siti. 2014. Efektifitas Metode Ceramah dengan Leaflet dalam Meningkatkan Pengetahuan Remaja tentang Seks Bebas di SMA Negri Ngrayun. Skripsi. Universitas Muhammadiyah Ponorogo.

Notoatmojo, Soekidjo. 2012. Pendidikan Kesehatan. Rineka Cipta, Jakarta.

Putra Cristian University Library. $2014 . \quad M e d i a$ Massa. http://digilib.petra.ac.id.
Simamora, R. H. 2017. A Strengthening of Role of Health Cadres in BTA-Positive Tuberculosis (TB) Case Invention Throught Education with Module Development and Video Approaches in Medan Padang Bulan Center, North Sumatera.

. 2019. Pengaruh Penyuluhan Identifikasi Pasien Dengan Menggunakan Media Audiovisual Terhadap Pengetahuan Pasien Rawat Inap. Jurnal Keperawatan Silampari. Volume 3, Nomor 1.

Slameto. 2010. Belajar dan Faktorfaktor yang Mempengaruhi. Rineka Cipta, Jakarta.

Wahid, Abdul dan Imam Suprapto. 2013. Keperawatan Medikal Bedah Asuhan Keperawatan Pada Gangguan Sistem Respirasi. Trans Info Media, Jakarta.

Wolagole, L. 2012, Gambaran Pengetahuan dan Sikap dalam Mengontrol Kekambuhan Asma pada Pasien Asma Bronkial Rawat Jalan Rumah Sakit Paru Dr. Ario Wirawan Salatiga. Skripsi. Program Studi IImi Keperawatan Fakultas IImu Kesehatan Universitas Kristen Satya Wacana. 